\title{
Dinâmica da avifauna em fragmento de mata na Fazenda Rio Claro, Lençóis Paulista, São Paulo, Brasil
}

\author{
Reginaldo José Donatelli ${ }^{1}$, Thiago Vernaschi Vieira da $\operatorname{Costa}^{2} \&$ Carolina Demetrio Ferreira ${ }^{2}$ \\ 1 Departamento de Ciências Biológicas, Faculdade de Ciências, Universidade Estadual Paulista. Caixa Postal 473, 17001-970 \\ Bauru, São Paulo, Brasil. \\ 2 Programa de Pós-graduação em Zoologia, Instituto de Biociências, Universidade Estadual Paulista. Rubião Júnior, 18618- \\ 100 Botucatu, São Paulo, Brasil.
}

\begin{abstract}
Avian community dynamics in a forest patch in the Fazenda Rio Claro, Lençóis Paulista, São Paulo, Brazil. This paper discusses a qualitative and quantitative survey of the avian community in the Fazenda Rio Claro $\left(22^{\circ} 27^{\prime} \mathrm{S}, 48^{\circ} 51^{\prime} \mathrm{W}\right)$, Lençóis Paulista, São Paulo State. The quantitative survey was conducted in the period August 2001-July 2002 using the Point Counts method. Diversity, frequency of occurrence (FO), abundance and evenness were measured for the community, which was classified into food categories and vertical occupancy of plant strata. The qualitative survey recorded 216 species, 82 of which were non-Passeriformes and 134 Passeriformes. The quantitative survey recorded 74 species and 761 contacts, with an average of 12.7 contacts per sample. The Abundance Index (IPA) varied from 0.001 (one contact) to 0.07 (53 contacts); the Diversity Index was $\mathrm{H}^{\prime}=3.10$, showing a significant increase between September and November. Evenness averaged 0.95. Insectivores accounted for almost half the total number of species recorded in the quantitative survey (44\%), followed by frugivores $(24.9 \%)$, omnivores $(16.4 \%)$, carnivores $(8.5 \%)$, detritivores $(1.4 \%)$, and a small proportion of nectarivores. Insectivores were the most abundant category in the understory, while frugivores were most abundant in the canopy and on the ground. The bird community of Fazenda Rio Claro is relatively stable, balanced and even in terms of richness, number of species, and IPA. Some endangered species are found in the area.
\end{abstract}

KEY WORDS. Birds, diversity, food category, forest community, patches.

RESUMO. Discute-se a importância do levantamento qualitativo e quantitativo da comunidade de aves da Fazenda Rio Claro $\left(22^{\circ} 27^{\prime} \mathrm{S}, 48^{\circ} 51^{\prime} \mathrm{W}\right)$, Lençóis Paulista, para a avaliação de um fragmento de mata mesófila do interior de São Paulo. Tais levantamentos foram realizados entre agosto de 2001 a julho de 2002. Para o estudo quantitativo utilizou-se da metodologia de Pontos de Escuta. Foram analisados os índices de diversidade e de freqüência de ocorrência dessa comunidade, sendo as suas espécies organizadas tanto em função das categorias alimentares quanto sob o aspecto da ocupação do estrato vegetal. O levantamento qualitativo registrou 216 espécies. Já o quantitativo registrou 74 espécies em 761 contatos, com uma média de 12,7 contatos/amostra. $O$ índice pontual de abundância (IPA) variou de 0,001 (um contato) a 0,07 (53 contatos); aquele da diversidade foi de $\mathrm{H}^{\prime}=3,10$, mostrando um aumento significativo entre setembro e novembro; a eqüitatividade média no período foi de $E=0,95$. Os insetívoros constituem quase a metade das espécies registradas no levantamento quantitativo $(44,6 \%)$, seguido por frugívoros $(24,9 \%)$, onívoros $(16,4 \%)$, carnívoros $(8,5 \%)$, nectarívoros $(4,2 \%)$ e uma pequena proporção de detritívoros $(1,4 \%)$. A categoria mais abundante no sub-bosque foi a de insetívoros, enquanto que os frugívoros foram os mais abundantes no solo e na copa. A comunidade de aves no fragmento estudado mostrou o mesmo padrão encontrado em outros fragmentos de mata mesófila de mesmo tamanho relativo. Algumas espécies ameaçadas foram encontradas na área de estudo.

PALAVRAS CHAVE. Aves, categoria alimentar, comunidade florestal, diversidade, fragmentos.

A diversidade ambiental do Estado de São Paulo, com relevos e tipos distintos de vegetação, abriga aproximadamente 738 espécies, o que corresponde a cerca de $45 \%$ das espécies da avifauna brasileira (SILVA 1998). A ação antrópica resultou na substituição de $80 \%$ da vegetação original do Estado, restando hoje ape- nas fragmentos isolados de alguns ecossistemas (CÂMARA 1990). Surpreendentemente, quase um quarto da avifauna paulista ocorre também em ambientes profundamente modificados pelo homem, como áreas de uso agropecuário, reflorestamentos, represamentos ou mesmo no interior das cidades (SILVA 1998). 
Os estudos realizados em ambientes fragmentados devem levar em conta não somente a área do fragmento em si, mas também o habitat circundante. Tais fragmentos raramente são circundados por um meio ecologicamente neutro ou inóspito, mas sofrem influências das áreas adjacentes, e seus efeitos podem ser mais importantes do que os processos que ocorrem dentro deles (Wiens 1994a,b, Terborgh 1980 apud Loiselle \& BLAKe 1992).

Habitats fragmentados afetam negativamente a sobrevivência de populações e a diversidade biológica, sendo então essa a primeira consideração para iniciar uma estratégia de conservação (WILcox \& Murphy 1985). Desta forma, um esforço de conservação bem sucedido requer conhecimento das causas e extensões da variação populacional, bem como das espécies remanescentes que estejam ou não em risco após a alteração de habitat (LoIselle \& BLAKE 1992).

As aves são um dos grupos animais mais distintos e bem estudados, podendo ser utilizadas como bio-indicadoras de alterações ambientais (VERNER 1981). O conhecimento das exigências ecológicas de muitas famílias, gêneros e espécies de aves pode ser suficiente em diversas situações para indicar condições ambientais às quais são sensíveis; portanto, alterações de vegetação implicam que o ambiente natural pode tornar-se impróprio para abrigar aves que exigem condições específicas para sobreviver.

O mote principal da pesquisa realizada foi o estudo qualitativo e quantitativo das aves que ocorrem na mata mesófila de planalto (Reserva do Rincão) na Fazenda Rio Claro, Lençóis Paulista, São Paulo. Define-se tal estudo como censo de aves em oposição a levantamento de aves, pois enquanto o primeiro nos fornece a dinâmica da comunidade de aves pela análise da abundância relativa dos indivíduos das espécies pertencentes a essa comunidade, o segundo nos fornece uma lista de espécies que serve como referencial para diversos estudos. Desta forma, a dinâmica reflete o desenvolvimento, a movimentação, a biologia e os comportamentos associados dessa comunidade de aves em uma determinada área ou região ao longo de uma unidade de tempo. O objetivo secundário caracteriza-se como estudo qualitativo ou exaustivo, pois promove o conhecimento da riqueza específica da comunidade de aves em um determinado local em um período em particular.

\section{MATERIAL E MÉTODOS}

\section{Área de estudo}

O estudo foi realizado na Fazenda Rio Claro $\left(22^{\circ} 27^{\prime} \mathrm{S}\right.$, $48^{\circ} 57^{\prime} \mathrm{W}$ ), área total de 21.854 ha, município de Lençóis Paulista, de propriedade da Duratex Florestal S.A. (Duraflora) no período de agosto de 2001 a julho de 2002 .

A fazenda localiza-se a $570 \mathrm{~m}$ de altitute, possui uma cobertura vegetal natural de aproximadamente 4 mil ha, sendo os tipos fisionômicos compostos de (valores aproximados): 1,6 mil ha de mata, 1,15 mil ha de várzea, 560 ha de vegetação campestre, 440 ha de cerradão, 20 ha de cerrado e 22 ha de capoeira (Duraflora 1999). Além disso, há diversos ambientes antropizados, como lagos e lagoas, bosques, jardins, pomares e viveiros dentre outros, os quais também são visitados por aves.

O estudo qualitativo na Fazenda Rio Claro cobriu áreas adjacentes à reserva do Rincão, formadas por vegetação campestre, cerrado e capoeiras, incluindo aquelas antropizadas. Já o estudo quantitativo ficou restrito exclusivamente à reserva do Rincão (cerca de 600 ha), incluindo o rio Claro, na porção em que este entra na mata. Foram utilizadas cinco trilhas préexistentes na mata de comprimento total variando de 250 a $1500 \mathrm{~m}$ para se evitar a abertura de novos caminhos. A "trilha da peroba" margeia o ribeirão Rio Claro enquanto que a trilha da várzea atinge uma regão alagada na mata; as demais, cortam transversalmente a mata. Um sorteio prévio foi realizado a cada amostragem para se determinar qual trilha seria utilizada em uma determinada amostragem.

\section{Levantamento qualitativo ou exaustivo}

Por definição de Vielliard \& Silva (1990), o levantamento exaustivo tem por finalidade estabelecer a lista mais completa possível da avifauna em uma determinada área de estudo. Tal levantamento não mede a abundância das espécies, mas se constitui da base de identificação das espécies, de seus ciclos biológicos e de suas preferências ambientais.

O protocolo ou roteiro de registro das espécies de aves vistas ou ouvidas seguiu a lista de espécies registradas por VIELLIARD \& SiLVA 1990) na forma de uma planilha de campo. Os dados da planilha foram transcritos para o programa Excel 2.0 do Microsoft Office programado para expressar freqüência de ocorrência.

O levantamento qualitativo foi realizado mensalmente no período de agosto de 2001 a julho de 2002, durante e após o censo quantitativo de aves e no final da tarde até o período noturno (próximo às 19:00 h). Foram realizados 12 levantamentos, sempre com os mesmos observadores $(n=3)$. O esforço amostral foi de oito horas de observação/visita, perfazendo um total de 96 horas de observação. As aves foram identificadas pelo método direto ou visual, sempre com a utilização de binóculos, ou por meio de suas vocalizações. Estas foram registradas com os seguintes tipos de gravadores e acessórios: Sony PROF II estéreo (cassete), Sony TCM 5000 EV (cassete) e Sony MD 127 mono (mini disk); microfone Sennheiser M66, Sennheiser M67 direcional e fones de ouvido Sennheiser (mono) e Philips (estéreo).

O cálculo do índice da freqüência de ocorrência seguiu Vielliard \& Silva (1990), ou seja, somente foi considerado o número de visitas onde a espécie foi registrada, sendo este índice expresso em porcentagem. Os coeficientes de riqueza e abundância foram os de Sorensen de acordo com KreBs (1999).

\section{Levantamento quantitativo}

Para o levantamento quantitativo da comunidade de aves foi utilizada a metodologia por Pontos de Escuta, idealizada 
por Blondel et al. (1970) para as regiões temperadas e adaptada por Vielliard \& Silva (1990) para as regiões tropicais.

No presente estudo foram efetuadas 12 visitas, uma por mês, entre agosto de 2001 e julho de 2002. O habitat amostrado foi a mata mesófila de planalto. Foram amostrados cinco pontos em cada visita, dentre um total de 36 pontos marcados, com duração de 20 minutos cada, no período matutino (início sempre 10 minutos antes do nascer do sol independente da estação do ano), totalizando 60 pontos amostrais. Tais pontos eram eqüidistantes $200 \mathrm{~m}$ entre si e eram sorteados antes de cada amostragem. Deste modo, seguiu-se a padronização utilizada por Vielliard \& Silva (1990), inclusive na mesma área de estudo, para que os resultados pudessem ser comparados. Os dados da planilha de campo foram transcritos para o programa Excel 2.0 do Microsoft Office programado para expressar riqueza, abundância, os índices pontuais de abundância e diversidade.

A nomenclatura das espécies seguiu Sick (1997) e a nomenclatura dos táxons supra-específicos seguiu a última edição do A. O. U. (American Ornithologist Union 1998).

\section{Guildas}

No presente estudo utilizou-se a definição de guildas de acordo com JAKSIC (1981), mas com a denominação categorias alimentares e estratificação vegetal. As primeiras foram determinadas em parte por observações diretas no campo, mas principalmente por meio da literatura especializada mais recente. O modelo utilizado para as categorias alimentares seguiu MоттA (1990), com algumas poucas modificações, sendo considerados: insetívoros (INS), dieta composta por 3/4 ou mais de insetos e outros artrópodes; onívoros (ONI), dieta composta por insetos, artrópodes e frutos, em proporções similares; frugívoros (FRU), dieta composta por 3/4 ou mais de frutos e grãos ou sementes; nectarívoros (NEC), dieta composta principalmente por néctar, mas também insetos e outros artrópodes; carnívoros (CAR): dieta composta por 3/4 ou mais de vertebrados vivos; detritívoros (DET): dieta composta por 3/4 ou mais de matéria orgânica em decomposição.

Para a classificação da ocupação das espécies no estrato vegetal foram considerados quatro estratos, a saber: solo (SL) espécies que utilizam preferencialmente o solo como local de forrageamento; intermediário (IN) -espécies que utilizam preferencialmente o estrato acima do solo até próximo a copa ou que utilizam o sub-bosque para forrageamento; superior (SU) - espécies que forrageiam preferencialmente na copa e acima dela; vertical (VR) - espécies que forrageiam verticalmente nos estratos vegetais.

\section{Diversidade}

O índice de diversidade utilizado neste trabalho foi o de Shannon-Wiener e a definição segue KrEBS (1999).

\section{Freqüência de ocorrência (FO\%)}

A Freqüência de Ocorrência (FO), expressa em porcentagem, determina a proporção dos dias em que cada espécie foi observada, em relação ao número total de dias de amostragem (Vielliard \& Silva 1990), sem se valer de dados quantitativos. Esse índice pode indicar o status (ocasional, residente, migrante) da espécie de acordo com o valor obtido.

\section{Abundância específica}

Foi calculada através do Índice Pontual de Abundância (IPA) que indica a abundância de cada espécie em função do seu coeficiente de conspicuidade, por meio do número de contatos visuais e/ou auditivos e o número total de amostras (Blondel et al. 1970). O número de contatos por ponto ou estação é a soma dos índices pontuais de abundância de cada espécie registrada naquele ponto. Para cada uma dessas espécies foi obtido um número de contatos que dividido pelo número de amostras representa o IPA desta espécie no local e período de estudo (Vielliard \& Silva 1990).

\section{RESULTADOS E DISCUSSÃO}

\section{Levantamento qualitativo ou exaustivo}

Foram registradas 216 espécies de aves na Fazenda Rio Claro (mata, áreas adjacentes à mata e áreas antropizadas) (Tab. I). Destas, 82 espécies pertencem à táxons de não-Passeriformes $(37,6 \%)$ e 134 pertencem à ordem Passeriformes (62,4\%). As espécies registradas estão distribuídas em 48 famílias, sendo 28 de não-Passeriformes e 20 de Passeriformes.

Vielliard \& Silva (1990) observaram na mesma Fazenda um total de 272 espécies de aves. O índice de similaridade do ambiente mata entre a composição específica registrada por Vielliard \& Silva (1990) e neste trabalho é de $\mathrm{S}_{\mathrm{s}}=82 \%$. A diferença entre esses valores ( $\mathrm{n}=54$ espécies) é estatisticamente pouco significativa $\left[\chi^{2}=6,42 \mathrm{p}<0,05\right]$, muito embora os autores tenham um número efetivamente maior de amostras ( $\mathrm{n}=$ 23), bem como tendo visitado habitats distintos na Fazenda Rio Claro. Pode-se afirmar a partir desses dados, que não houve variação significativa em termos de composição específica na Fazenda Rio Claro nos últimos 18 anos. Se considerarmos algumas espécies, que foram observadas por Vielliard \& Silva (1990) e não foram registradas nas 12 amostras, tem-se o seguinte quadro: seis espécies são aquáticas e/ou migratórias dentro das Américas Central e do Sul (e.g. Laterallus melanophaius (Vieillot, 1819) e L. leucopyrrhus (Vieillot, 1819) e 24 pertencem a áreas abertas, particularmente ao cerrado; quatro são potencialmente migratórias, sendo que duas são migratórias da América do Norte (Hirundo rustica Linnaeus, 1758; Hirundo pyrrhonota Vieillot, 1817); as demais $(\mathrm{n}=20)$ realmente não foram constatadas, particularmente alguns Trochilidae; podese destacar ainda Tinamus solitarius (Vieillot, 1819), Nothura maculosa (Temminck, 1815), sendo a primeira espécie provavelmente extinta na área; Elanus leucurus Vieillot 1818 avistada somente fora da área em questão; e alguns Fringilidae que habitam áreas com gramíneas altas e campos (pertencentes ao gênero Sporophila, como, S. bouvreuil (Müller, 1776) e $S$. leucoptera (Vieillot, 1817).

Revista Brasileira de Zoologia 21 (1): 97-114, março 2004 
Tabela I. Freqüência de ocorrência, índice pontual de abundância, categorias alimentares e estrato vegetal de preferência das espécies de aves da Fazenda Rio Claro, Lençóis Paulista, São Paulo. (F.O.) Freqüência de ocorrência, (I.P.A.) índice pontual de abundância, (a) espécies ameaçadas, (pa) espécies provavelmente ameaçadas.

\begin{tabular}{|c|c|c|c|c|}
\hline Espécies & F.O. (\%) & I.P.A. & Categoria alimentar & Estrato vegetal \\
\hline \multicolumn{5}{|l|}{ Tinamidae } \\
\hline Crypturellus obsoletus (Temminck, 1815) & 75,00 & 0,014 & frugívoro & solo \\
\hline Crypturellus parvirostris (Wagler, 1827) & 16,67 & & frugívoro & solo \\
\hline Crypturellus tataupa (Temminck, 1815) & 8,33 & 0,001 & frugívoro & solo \\
\hline Rhynchotus rufescens (Temminck, 1815) & 8,33 & & frugívoro & solo \\
\hline \multicolumn{5}{|l|}{ Podicipedidae } \\
\hline Podilymbus podiceps (Linnaeus, 1758) & 8,33 & & carnívoro & \\
\hline Tachybaptus dominicus (Linnaeus, 1766) & 0 & & carnívoro & \\
\hline \multicolumn{5}{|l|}{ Phalacrocoracidae } \\
\hline Phalacrocorax brasilianus (Gmelin, 1789) & 8,33 & & carnívoro & \\
\hline \multicolumn{5}{|l|}{ Anhingidae } \\
\hline Anhinga anhinga Linnaeus, 1766 & 0 & & carnívoro & \\
\hline \multicolumn{5}{|l|}{ Ardeidae } \\
\hline Ardea cocoi Linnaeus, 1766 & 0 & & carnívoro & solo \\
\hline Casmerodius albus (Linnaeus, 1758) & 33,33 & & carnívoro & solo \\
\hline Egretta thula (Molina, 1782) & 0 & & carnívoro & solo \\
\hline Syrigma sibilatrix (Temminck, 1824) & 25,00 & & insetívoro & solo \\
\hline Butorides striatus (Linnaeus, 1758) & 16,67 & & carnívoro & solo \\
\hline Nycticorax nycticorax (Linnaeus, 1758) & 0 & & carnívoro & \\
\hline Tigrisoma lineatum (Vieillot, 1817) & 0 & & carnívoro & solo \\
\hline \multicolumn{5}{|l|}{ Threskiornithidae } \\
\hline Mesembrinibis cayennensis (Gmelin, 1789) & 8,33 & & onívoro & solo \\
\hline \multicolumn{5}{|l|}{ Anatidae } \\
\hline Cairina moschata (Linnaeus, 1758) & 66,67 & & carnívoro & \\
\hline Amazonetta brasiliensis (Gmelin, 1789) & 0 & & carnívoro & \\
\hline \multicolumn{5}{|l|}{ Cathartidae } \\
\hline Cathartes aura (Linnaeus, 1758) & 25,00 & & detritívoro & superior \\
\hline Coragyps atratus (Bechstein, 1793) & 33,33 & & detritívoro & superior \\
\hline Sarcoramphus papa (Linnaeus, 1758) a & 8,33 & & detritívoro & superior \\
\hline \multicolumn{5}{|l|}{ Acciptridae } \\
\hline Ictinia plumbea (Gmelin, 1788) & 41,67 & & carnívoro & superior \\
\hline Rupornis magnirostris (Bertoni, 1901) & 66,67 & 0,003 & carnívoro & superior \\
\hline Buteo albicaudatus Vieillot, 1816 & 0 & & & \\
\hline Circus buffoni (Gmelin, 1788) pa & 0 & & carnívoro & superior \\
\hline \multicolumn{5}{|l|}{ Falconidae } \\
\hline Caracara plancus (Miller, 1777) & 16,67 & & carnívoro & solo \\
\hline Milvago chimachima (Vieillot, 1816) & 16,67 & & carnívoro & superior \\
\hline Herpetotheres cachinnans (Linnaeus, 1758) & 41,67 & 0,007 & carnívoro & superior \\
\hline
\end{tabular}


Tabela I. Continuação.

\begin{tabular}{|c|c|c|c|c|}
\hline Espécies & F.O. (\%) & I.P.A. & Categoria alimentar & Estrato vegetal \\
\hline Micrastur ruficollis (Vieillot, 1817) & 8,33 & & carnívoro & intermediário \\
\hline Micrastur semitorquatus (Vieillot, 1817) & 8,33 & 0,001 & carnívoro & superior \\
\hline Falco sparverius Linnaeus, 1758 & 0 & & carnívoro & superior \\
\hline Falco femoralis Temminck, 1822 & 0 & & carnívoro & solo \\
\hline \multicolumn{5}{|l|}{ Cracidae } \\
\hline Penelope superciliaris Spix, 1825 & 25,00 & 0,003 & frugívoro & intermediário \\
\hline \multicolumn{5}{|l|}{ Phasianidae } \\
\hline Odontophorus capueira (Spix, 1825) & 8,33 & & onívoro & solo \\
\hline \multicolumn{5}{|l|}{ Rallidae } \\
\hline Aramides cajanea Müller, 1776 & 8,33 & & onívoro & solo \\
\hline Gallinula chloropus (Linnaeus, 1758) & 25,00 & & onívoro & solo \\
\hline \multicolumn{5}{|l|}{ Cariamidae } \\
\hline Cariama cristata (Linnaeus, 1766) & 75,00 & 0,005 & carnívoro & solo \\
\hline \multicolumn{5}{|l|}{ Jacanidae } \\
\hline Jacana jacana (Linnaeus, 1766) & 8,33 & & carnívoro & solo \\
\hline \multicolumn{5}{|l|}{ Charadriidae } \\
\hline Vanellus chilensis (Molina, 1782) & 50,00 & & onívoro & solo \\
\hline \multicolumn{5}{|l|}{ Columbidae } \\
\hline Columba picazuro Temminck, 1813 & 100,00 & 0,048 & frugívoro & solo \\
\hline Columba cayennensis Vielliot, 1818 & 66,67 & 0,022 & frugívoro & superior \\
\hline Zenaida auriculata (Des Murs, 1847) & 50,00 & & frugívoro & intermediário \\
\hline Columbina talpacoti (Temminck, 1811) & 75,00 & & frugívoro & solo \\
\hline Claravis pretiosa (Ferrari-Perez, 1886) & 8,33 & & frugívoro & solo \\
\hline Scardafella squammata (Lesson, 1831) & 50,00 & & frugívoro & solo \\
\hline Leptotila verreauxi Giglioli \& Salvadori, 1870 & 25,00 & & frugívoro & intermediário \\
\hline Leptotila rufaxilla Pelzeln, 1870 & 16,67 & & frugívoro & intermediário \\
\hline Geotrygon montana (Linnaeus, 1758) & 33,33 & 0,005 & frugívoro & solo \\
\hline \multicolumn{5}{|l|}{ Psittacidae } \\
\hline Primolius maracana (Vieillot, 1816) a & 8,33 & & frugívoro & superior \\
\hline Aratinga leucophthalmus (Müller, 1776) & 41,67 & 0,012 & frugívoro & superior \\
\hline Forpus xanthopterygius (Spix, 1824) & 41,67 & & frugívoro & superior \\
\hline Pionus maximiliani Miranda Ribeiro, 1920 & 41,67 & 0,009 & frugívoro & superior \\
\hline Amazona aestiva (Linnaeus, 1758) a & 33,33 & 0,014 & frugívoro & superior \\
\hline \multicolumn{5}{|l|}{ Cuculidae } \\
\hline Piaya cayana Gambel, 1849 & 83,33 & 0,008 & onívoro & superior \\
\hline Crotophaga ani Linnaeus, 1758 & 33,33 & & insetívoro & intermediário \\
\hline Guira guira (Gmelin, 1788) & 33,33 & & insetívoro & intermediário \\
\hline Tapera naevia (Vieillot, 1817) & 41,67 & 0,004 & insetívoro & intermediário \\
\hline Dromococcyx pavoninus Pelzeln, 1870 & 16,67 & & carnívoro & solo \\
\hline
\end{tabular}


Tabela I. Continuação.

\begin{tabular}{|c|c|c|c|c|}
\hline Espécies & F.O. (\%) & I.P.A. & Categoria alimentar & Estrato vegetal \\
\hline \multicolumn{5}{|l|}{ Tytonidae } \\
\hline Tyto alba (Scopoli, 1769) & 8,33 & & carnívoro & superior \\
\hline \multicolumn{5}{|l|}{ Strigidae } \\
\hline Otus choliba (Vieillot, 1817) & 25,00 & & insetívoro & superior \\
\hline Glaucidium brasilianum (Gmelin, 1788) & 8,33 & 0,001 & insetívoro & solo \\
\hline \multicolumn{5}{|l|}{ Caprimulgidae } \\
\hline Lurocalis semitorquatus (Temminck, 1822) & 16,67 & 0,005 & insetívoro & superior \\
\hline Nyctidromus albicollis Gould, 1838 & 8,33 & & insetívoro & solo \\
\hline Caprimulgus rufus (Burmeister, 1856) & 8,33 & & insetívoro & intermediário \\
\hline Caprimulgus parvulus Gould, 1837 & 50,00 & & insetívoro & solo \\
\hline Hydropsalis brasiliana (Vieillot, 1817) & 25,00 & & insetívoro & solo \\
\hline \multicolumn{5}{|l|}{ Trochilidae } \\
\hline Phaethornis pretrei (Lesson \& Delattre, 1839) & 50,00 & & nectarívoro & intermediário \\
\hline Eupetomena macroura (Gmelin, 1788) & 25,00 & & nectarívoro & intermediário \\
\hline Melanotrochilus fuscus (Vieillot, 1817) & 25,00 & 0,001 & nectarívoro & intermediário \\
\hline Anthracothorax nigricollis (Vieillot, 1817) & 8,33 & & nectarívoro & superior \\
\hline Chlorostilbon aureoventris Bourcier \& Mulsant, 1848 & 25,00 & & nectarívoro & intermediário \\
\hline Thalurania glaucopis (Gmelin, 1788) & 33,33 & 0,001 & nectarívoro & intermediário \\
\hline Hylocharis chrysura (Shaw, 1812) & 8,33 & 0,001 & nectarívoro & superior \\
\hline Amazilia versicolor Ruschi, 1959 & 8,33 & & nectarívoro & \\
\hline \multicolumn{5}{|l|}{ Trogonidae } \\
\hline Trogon rufus Pelzeln, 1856 & 8,33 & 0,001 & onívoro & superior \\
\hline Trogon surrucura Vieillot, 1817 & 66,67 & 0,018 & onívoro & superior \\
\hline \multicolumn{5}{|l|}{ Alcedinidae } \\
\hline Ceryle torquata (Linnaeus, 1766) & 50,00 & 0,001 & carnívoro & superior \\
\hline Chloroceryle amazona (Latham, 1790) & 25,00 & & carnívoro & intermediário \\
\hline \multicolumn{5}{|l|}{ Momotidae } \\
\hline Baryphthengus ruficapillus (Vieillot, 1818) & 75,00 & 0,023 & onívoro & superior \\
\hline \multicolumn{5}{|l|}{ Galbulidae } \\
\hline Galbula ruficauda Cabanis, 1851 & 41,67 & & insetívoro & intermediário \\
\hline \multicolumn{5}{|l|}{ Bucconidae } \\
\hline Nystalus chacuru (Vieillot, 1816) & 25,00 & & insetívoro & superior \\
\hline Malacoptila striata (Spix, 1824) & 16,67 & & insetívoro & superior \\
\hline \multicolumn{5}{|l|}{ Ramphastidae } \\
\hline Ramphastos toco Cabanis, 1862 & 25,00 & 0,009 & onívoro & superior \\
\hline \multicolumn{5}{|l|}{ Picidae } \\
\hline Picumnus albosquamatus Sundevall, 1866 & 100,00 & 0,031 & insetívoro & vertical \\
\hline Melanerpes candidus (Otto, 1796) & 8,33 & & insetívoro & vertical \\
\hline Veniliornis passerinus (Natterer \& Malherbe, 1845) & 16,67 & & insetívoro & vertical \\
\hline
\end{tabular}


Tabela I. Continuação.

\begin{tabular}{|c|c|c|c|c|}
\hline Espécies & F.O. (\%) & I.P.A. & Categoria alimentar & Estrato vegetal \\
\hline Veniliornis spilogaster (Wagler, 1827) & 16,67 & & insetívoro & vertical \\
\hline Colaptes melanochloros (Malherbe, 1848) & 8,33 & & insetívoro & superior \\
\hline Colaptes campestris (Vieillot, 1818) & 50,00 & & insetívoro & solo \\
\hline Celeus flavescens (Gmelin, 1788) & 8,33 & & insetívoro & vertical \\
\hline Dryocopus lineatus (Linnaeus, 1766) & 25,00 & 0,001 & insetívoro & vertical \\
\hline \multicolumn{5}{|l|}{ Dendrocolaptidae } \\
\hline Sittasomus griseicapillus (Temminck, 1821) & 100,00 & 0,035 & insetívoro & vertical \\
\hline Dendrocolaptes platyrostris Spix, 1825 & 50,00 & 0,008 & insetívoro & vertical \\
\hline Lepidocolaptes angustirostris (Lichtenstein, 1822) & 8,33 & & insetívoro & vertical \\
\hline Lepidocolaptes fuscus (Vieillot, 1818) & 91,67 & 0,022 & insetívoro & vertical \\
\hline \multicolumn{5}{|l|}{ Furnariidae } \\
\hline Furnarius rufus (Lichtenstein, 1823) & 58,33 & & insetívoro & solo \\
\hline Synallaxis ruficapilla Vieillot, 1819 & 91,67 & 0,040 & insetívoro & intermediário \\
\hline Synallaxis frontalis Pelzeln, 1859 & 41,67 & & insetívoro & intermediário \\
\hline Synallaxis spixi Sclater, 1856 & 41,67 & & insetívoro & intermediário \\
\hline Certhiaxis cinnamomea (Vieillot, 1817) & 8,33 & & insetívoro & \\
\hline Cranioleuca vulpina (Pelzeln, 1856) & 8,33 & & insetívoro & \\
\hline Lochmias nematura (Lichtenstein, 1823) & 16,67 & & insetívoro & solo \\
\hline Automolus leucophthalmus (Lichtenstein, 1823) & 83,33 & 0,033 & insetívoro & intermediário \\
\hline Xenops rutilans Temminck, 1821 & 8,33 & 0,001 & insetívoro & superior \\
\hline \multicolumn{5}{|l|}{ Formicariidae } \\
\hline Mackenziaena severa (Lichtenstein, 1823) & 75,00 & 0,014 & insetívoro & intermediário \\
\hline Taraba major (Vieillot, 1816) & 33,33 & 0,001 & insetívoro & intermediário \\
\hline Thamnophilus doliatus Vieillot, 1816 & 41,67 & 0,008 & insetívoro & intermediário \\
\hline Thamnophilus punctatus Hellmayr, 1924 & 25,00 & & insetívoro & intermediário \\
\hline Thamnophilus caerulescens Vieillot, 1816 & 91,67 & 0,033 & insetívoro & intermediário \\
\hline Thamnophilus ruficapillus Vieillot, 1816 & 8,33 & & insetívoro & \\
\hline Dysithamnus mentalis (Temminck, 1823) & 66,67 & 0,017 & insetívoro & intermediário \\
\hline Herpsilochmus rufimarginatus (Temminck, 1822) & 25,00 & 0,003 & insetívoro & superior \\
\hline Drymophila malura Temminck, 1825 & 8,33 & 0,001 & insetívoro & intermediário \\
\hline Pyriglena leucoptera (Vieillot, 1818) & 50,00 & 0,017 & insetívoro & intermediário \\
\hline Formicivora rufa (Lafresnaye \& d'Orbigny, 1837) & 8,33 & & insetívoro & intermediário \\
\hline \multicolumn{5}{|l|}{ Conopophagidae } \\
\hline Conopophaga lineata Ménétriès, 1885 & 100,00 & 0,039 & insetívoro & intermediário \\
\hline \multicolumn{5}{|l|}{ Rhynocryptidae } \\
\hline Melanopareia torquata Hellmayr, $1924^{\text {a }}$ & 8,33 & & insetívoro & solo \\
\hline Scytalopus indigoticus (Wied, 1831) & 58,33 & 0,012 & insetívoro & solo \\
\hline \multicolumn{5}{|l|}{ Tyrannidae } \\
\hline Camptostoma obsoletum (Temminck, 1824) & 58,33 & 0,004 & insetívoro & superior \\
\hline
\end{tabular}


Tabela I. Continuação.

\begin{tabular}{|c|c|c|c|c|}
\hline Espécies & F.O. (\%) & I.P.A. & Categoria alimentar & Estrato vegetal \\
\hline Phaeomyias murina (Spix, 1825) & 8,33 & & insetívoro & superior \\
\hline Elaenia flavogaster (Thumberg, 1822) & 66,67 & & onívoro & superior \\
\hline Elaenia chiriquensis Pelzeln, 1868 & 8,33 & & onívoro & superior \\
\hline Elaenia obscura Zimmer, 1941 & 8,33 & & onívoro & superior \\
\hline Serpophaga subcristata (Vieillot, 1817) & 25,00 & & insetívoro & superior \\
\hline Leptopogon amaurocephalus Tschudi, 1846 & 8,33 & & insetívoro & intermediário \\
\hline Corythopis delalandi (Lesson, 1830) & 100,00 & 0,044 & insetívoro & intermediário \\
\hline Todirostrum latirostre (Allen, 1889) & 33,33 & 0,005 & insetívoro & superior \\
\hline Todirostrum cinereum Ridgway, 1906 & 16,67 & & insetívoro & intermediário \\
\hline Tolmomyias sulphurescens (Spix, 1825) & 33,33 & 0,007 & insetívoro & superior \\
\hline Platyrinchus mystaceus Vieillot, 1818 & 50,00 & 0,022 & insetívoro & intermediário \\
\hline Myiophobus fasciatus (Temminck, 1822) & 8,33 & & insetívoro & intermediário \\
\hline Lathrotriccus euleri (Cabanis, 1868) & 58,33 & 0,012 & insetívoro & intermediário \\
\hline Cnemotriccus fuscatus (Lafresnaye \& d'Orbigny, 1837) & 25,00 & 0,001 & insetívoro & intermediário \\
\hline Pyrocephalus rubinus (Boddaert, 1783) & 8,33 & & insetívoro & superior \\
\hline Xolmis cinerea (Vieillot, 1816) & 8,33 & & insetívoro & intermediário \\
\hline Xolmis velata (Lichtenstein, 1823) & 8,33 & & insetívoro & solo \\
\hline Fluvicola nengeta (Linnaeus, 1766) & 8,33 & & insetívoro & solo \\
\hline Colonia colonus (Vieillot, 1818) & 41,67 & & insetívoro & superior \\
\hline Gubernetes yetapa (Vieillot, 1818) & 8,33 & & insetívoro & superior \\
\hline Satrapa icterophrys (Vieillot, 1818) & 50,00 & & insetívoro & intermediário \\
\hline Hirundinea ferruginea (Vieillot, 1819) & 8,33 & & insetívoro & superior \\
\hline Machetornis rixosus (Vieillot, 1819) & 25,00 & & insetívoro & solo \\
\hline Myiarchus swainsoni Cabanis \& Heine, 1859 & 8,33 & & insetívoro & intermediário \\
\hline Myiarchus ferox (Hellmayr, 1927) & 41,67 & & insetívoro & intermediário \\
\hline Myiarchus tyrannulus Berlepsch \& Leverkühn, 1890 & 33,33 & & insetívoro & intermediário \\
\hline Pitangus sulphuratus (Cabanis \& Heine, 1859) & 83,33 & 0,003 & insetívoro & superior \\
\hline Megarhynchus pitangua (Linnaeus, 1766) & 83,33 & 0,001 & insetívoro & superior \\
\hline Myiozetetes similis Pinto, 1935 & 58,33 & & insetívoro & superior \\
\hline Myiodynastes maculatus (Vieillot, 1819) & 41,67 & 0,007 & insetívoro & superior \\
\hline Legatus leucophaius (Vieillot, 1818) & 16,67 & & insetívoro & intermediário \\
\hline Empidonomus varius (Vieillot, 1818) & 8,33 & & insetívoro & intermediário \\
\hline Tyrannus melancholicus Vieillot, 1819 & 58,33 & & insetívoro & superior \\
\hline Tyrannus savanna (Linnaeus, 1766) & 50,00 & & insetívoro & \\
\hline Pachyramphus polychopterus (Swainson, 1837) & 16,67 & 0,003 & onívoro & superior \\
\hline Pachyramphus validus (Lichtenstein, 1823) & 33,33 & & onívoro & superior \\
\hline Tityra cayana (Swainson, 1837) & 50,00 & 0,004 & insetívoro & superior \\
\hline Tityra inquisitor (Lichtenstein, 1823) & 8,33 & 0,001 & insetívoro & superior \\
\hline Arundinicola leucocephala (Linnaeus, 1764) & 8,33 & & insetívoro & \\
\hline
\end{tabular}


Tabela I. Continuação.

\begin{tabular}{|c|c|c|c|c|}
\hline Espécies & F.O. (\%) & I.P.A. & Categoria alimentar & Estrato vegetal \\
\hline \multicolumn{5}{|l|}{ Pipridae } \\
\hline Schiffornis virescens (Lafresnaye, 1838) & 25,00 & 0,003 & frugívoro & intermediário \\
\hline Antilophia galeata (Lichtenstein, 1823) ${ }^{a}$ & 8,33 & & frugívoro & intermediário \\
\hline Chiroxiphia caudata (Shaw \& Nodder, 1793) & 91,67 & 0,034 & frugívoro & intermediário \\
\hline \multicolumn{5}{|l|}{ Cotingidae } \\
\hline Procnias nudicollis (Vieillot, 1817) ${ }^{a}$ & 8,33 & 0,001 & frugívoro & superior \\
\hline \multicolumn{5}{|l|}{ Hirundinidae } \\
\hline Progne chalybea (Vieillot, 1817) & 58,33 & & insetívoro & superior \\
\hline Notiochelidon cyanoleuca (Vieillot, 1817) & 66,67 & & insetívoro & superior \\
\hline Stelgidopteryx ruficollis (Vieillot, 1817) & 58,33 & & insetívoro & superior \\
\hline \multicolumn{5}{|l|}{ Troglodytidae } \\
\hline Troglodytes musculus Naumann, 1823 & 50,00 & & onívoro & intermediário \\
\hline \multicolumn{5}{|l|}{ Mimidae } \\
\hline Mimus saturninus Hellmayr, 1903 & 50,00 & & onívoro & superior \\
\hline \multicolumn{5}{|l|}{ Turdidae } \\
\hline Turdus nigriceps Cabanis, 1874 & 8,33 & & onívoro & intermediário \\
\hline Turdus rufiventris Vieillot, 1818 & 83,33 & 0,012 & onívoro & intermediário \\
\hline Turdus leucomelas Vieillot, 1818 & 41,67 & 0,003 & onívoro & intermediário \\
\hline Turdus amaurochalinus Cabanis, 1851 & 41,67 & 0,001 & onívoro & intermediário \\
\hline Turdus albicollis Vieillot, 1818 & 25,00 & 0,007 & onívoro & intermediário \\
\hline \multicolumn{5}{|l|}{ Emberizidae } \\
\hline Zonotrichia capensis Swainson, 1837 & 75,00 & & frugívoro & solo \\
\hline Ammodramus humeralis (Bosc, 1792) & 25,00 & & frugívoro & \\
\hline Sicalis flaveola (Gmelin, 1766) & 33,33 & & frugívoro & \\
\hline Emberizoides herbicola (Vieillot, 1817) & 16,67 & & frugívoro & \\
\hline Volatinia jacarina (Linnaeus, 1766) & 50,00 & & frugívoro & \\
\hline Sporophila lineola (Linnaeus, 1758) & 33,33 & & onívoro & \\
\hline Sporophila caerulescens (Vieillot, 1817) & 41,67 & & onívoro & \\
\hline Oryzoborus angolensis (Linnaeus, 1766) ${ }^{a}$ & 8,33 & & frugívoro & \\
\hline Arremon flavirostris Des Murs, 1856 & 50,00 & & frugívoro & intermediário \\
\hline Coryphospingus cucullatus (Swainson, 1825) & 33,33 & & frugívoro & intermediário \\
\hline Pytilus fuliginosus (Daudin, 1800) & 91,67 & 0,047 & frugívoro & intermediário \\
\hline Saltator similis Lafresnaye \& d'Orbigny, 1837 & 25,00 & 0,005 & frugívoro & intermediário \\
\hline Saltator atricollis Vieillot, $1817^{a}$ & 16,67 & & frugívoro & intermediário \\
\hline Passerina brissonii (Lichtenstein, 1823) ${ }^{a}$ & 8,33 & & frugívoro & \\
\hline Schistochlamys ruficapillus (Vieillot, 1817) & 8,33 & & frugívoro & \\
\hline \multicolumn{5}{|l|}{ Thraupidae } \\
\hline Neothraupis fasciata (Lichtenstein, 1823) & 8,33 & & frugívoro & superior \\
\hline Thlypopsis sordida (d'Orbigny \& Lafresnaye, 1837) & 8,33 & & frugívoro & superior \\
\hline Nemosia pileata Chubb, 1910 & 16,67 & & frugívoro & \\
\hline
\end{tabular}


Tabela I. Continuação.

\begin{tabular}{|c|c|c|c|c|}
\hline Espécies & F.O. (\%) & I.P.A. & Categoria alimentar & Estrato vegetal \\
\hline Tachyphonus coronatus (Vieillot, 1822) & 58,33 & 0,010 & frugívoro & superior \\
\hline Trichothraupis melanops (Vieillot, 1818) & 16,67 & & frugívoro & intermediário \\
\hline Habia rubica (Vieillot, 1817) & 16,67 & 0,003 & insetívoro & intermediário \\
\hline Piranga flava (Spix, 1825) & 8,33 & & frugívoro & \\
\hline Ramphocelus carbo Hellmayr, 1920 & 33,33 & & frugívoro & intermediário \\
\hline Thraupis sayaca (Linnaeus, 1766) & 50,00 & & frugívoro & superior \\
\hline Pipraeidea melanonota (Vieillot, 1819) & 8,33 & & frugívoro & superior \\
\hline Euphonia chlorotica (d'Orbigny \& Lafresnaye, 1837) & 75,00 & 0,005 & frugívoro & superior \\
\hline Euphonia violacea (Bertoni, 1901) & 16,67 & & frugívoro & superior \\
\hline Euphonia cyanocephala (Vieillot, 1818) & 8,33 & & frugívoro & \\
\hline Tangara cayana (Vieillot, 1819) & 41,67 & & frugívoro & superior \\
\hline Dacnis cayana Chubb, 1910 & 33,33 & & frugívoro & superior \\
\hline Conirostrum speciosum (Temminck, 1824) & 8,33 & & insetívoro & superior \\
\hline \multicolumn{5}{|l|}{ Tersinidae } \\
\hline Tersina viridis (Illiger, 1811) & 41,67 & & onívoro & superior \\
\hline \multicolumn{5}{|l|}{ Coerebidae } \\
\hline Coereba flaveola (Cabanis, 1851) & 41,67 & & nectarívoro & \\
\hline \multicolumn{5}{|l|}{ Parulidae } \\
\hline Parula pitiayumi (Vieillot, 1817) & 41,67 & & insetívoro & superior \\
\hline Geothlypis aequinoctialis (Vieillot, 1807) & 16,67 & & insetívoro & superior \\
\hline Basileuterus flaveolus (Baird, 1865) & 91,67 & 0,009 & insetívoro & intermediário \\
\hline Basileuterus culicivorus (Deppe,1830) & 100,00 & 0,069 & insetívoro & intermediário \\
\hline Basileuterus leucoblepharus (Vieillot, 1817) & 100,00 & 0,059 & insetívoro & intermediário \\
\hline \multicolumn{5}{|l|}{ Vireonidae } \\
\hline Cyclarhis gujanensis Baird, 1866 & 100,00 & 0,050 & insetívoro & intermediário \\
\hline Vireo chivi (Vieillot, 1817) & 50,00 & 0,029 & onívoro & intermediário \\
\hline Hylophilus poicilotis Temminck, 1822 & 25,00 & & insetívoro & superior \\
\hline \multicolumn{5}{|l|}{ Icteridae } \\
\hline Icterus jamacaii (Gmelin, 1788) & 8,33 & & onívoro & \\
\hline Agelaius cyanopus Vieillot, 1819 & 8,33 & & onívoro & solo \\
\hline Agelaius ruficapillus Vieillot, 1819 & 16,67 & & onívoro & solo \\
\hline Pseudoleistes guirahuro (Vieillot, 1819) & 16,67 & & onívoro & solo \\
\hline Gnorimopsar chopi (Vieillot, 1819) & 16,67 & & onívoro & solo \\
\hline Molothrus bonariensis (Gmelin, 1789) & 8,33 & & onívoro & solo \\
\hline \multicolumn{5}{|l|}{ Fringillidae } \\
\hline Carduelis magellanica (Vieillot, 1805) & 25,00 & & frugívoro & superior \\
\hline \multicolumn{5}{|l|}{ Passeridae } \\
\hline Passer domesticus (Linnaeus, 1758) & 33,33 & & onívoro & \\
\hline \multicolumn{5}{|l|}{ Corvidae } \\
\hline Cyanocorax cristatellus (Temminck, 1823) & 25,00 & & onívoro & superior \\
\hline Cyanocorax chrysops (Vieillot, 1818) & 50,00 & & onívoro & superior \\
\hline
\end{tabular}


Por outro lado, registramos 28 espécies não observadas por aqueles autores, sendo 10 espécies aquáticas, nove de ocorrência ocasional e cinco migratórias. As demais ocorrem regularmente na área: Pachyramphus validus (Lichtenstein, 1823), Ammodramus humeralis (Bosc, 1792) e Passerina brissonii (Lichtenstein, 1823).

Outros autores estudaram a composição específica da comunidade de aves na região: MagalHães (1999) em seu estudo da mata mesófila na Fazenda Barreiro Rico (2.200 ha) por mais de 40 anos registrou 351 espécies, incluindo o macuco (Tinamus solitarius). Willis \& ONIKY (1981) registraram 185 espécies na Reserva Florestal do Morro do Diabo (37.000 ha) após 55 h de observação. Na Fazenda Santa Genebra, região de Campinas, Aleixo \& Vielliard (1995) registraram 134 espécies em um área de 250 ha de mata.

Mantidas as devidas proporções e descontados os diferentes esforços amostrais em cada caso descrito, todos esses dados ilustram a importância dos fragmentos florestais de mata semidecídua na conservação de aves, incluindo-se espécies com hábito alimentar restrito ou mais especializadas (ver adiante), fato este que reflete uma necessidade cada vez maior de preservar esses fragmentos (como é o caso da reserva do Rincão na Fazenda Rio Claro). Todavia, se comparado com dados de mais de duas décadas, verificar-se-á um desaparecimento de um número significativo de espécies de aves no planalto paulista, particularmente na região centro-oeste, local de nosso estudo e análise comparativa com outros trabalhos desenvolvidos na região (ver Magalhães 1999, talvez a obra que mais ilustra esta afirmação).

A freqüência de ocorrência (FO\%) da comunidade de aves da Fazenda Rio Claro é apresentada na tabela II e expressa em classes de porcentagem.

Tabela II. Freqüência de ocorrência (\%) da comunidade de aves na fazenda Rio Claro, Lençóis Paulista, São Paulo.

\begin{tabular}{llllllll}
\hline & \multicolumn{6}{c}{ Classes de porcentagem (\%) } \\
\cline { 2 - 8 } & Até 24 & $25-50$ & $51-75$ & $76-99$ & 100 & Total \\
\hline Porcentagem relativa & 41,0 & 40,3 & 10,2 & 5,5 & 3,0 & 100 \\
Número de espécies & 88 & 87 & 22 & 12 & 7 & 216 \\
\hline
\end{tabular}

Com 96 horas de observação e 12 amostras, pode-se inferir que a curva estabilizadora do número de espécies (Fig. 1) não foi atingida e que seriam necessárias mais horas (mais amostras) para otimizar a relação dos dados obtidos.

WilLIs \& ONIKI (1981) afirmam que a curva se estabilizaria após 200 horas de observação e mesmo assim poder-se-ia encontrar "novas" espécies. Naturalmente estes autores referem-se a espécies ocasionais e não residentes, migratórias e visitantes sazonais. Pode-se inferir a partir desses dados que cerca de $60 \%$ das espécies são residentes (mínimo de uma ocor-

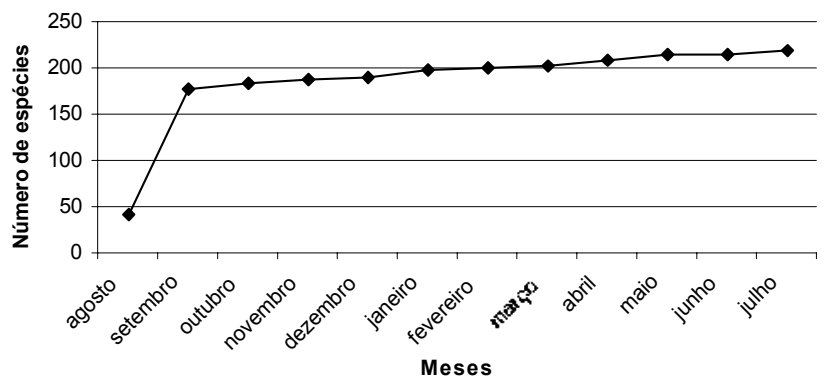

Fig. 1. Curva cumulativa do número de espécies registrado mensalmente na Fazenda Rio Claro, Lençóis Paulista, São Paulo, entre agosto de 2001 a julho de 2002.

rência a cada quatro visitas); as demais são de status indefinido. Mesmo assim, seria necessário criar categorias fenológicas da presença de várias espécies, como advogam Vielliard \& SiLva (1990). Interessante notar que estes autores constataram valores dissimilares inclusive para aquelas espécies de aves mais freqüentemente encontradas (com F.O. $=100 \%$ ), igual a 10\%, enquanto neste trabalho encontrou-se 3\%. Esta diferença está coerente com os dados de freqüência de ocorrência global obtidas por aqueles autores e este trabalho e com a composição específica registrada em ambos os casos. Difere, entretanto, em relação ao coeficiente de similaridade utilizado, uma vez que $82 \%$ das espécies foram registradas em ambos estudos. Isto pode significar que uma determinada espécie de ave ainda se encontra na área ou região 18 anos depois, mas que a sua densidade pode ter sido diminuída nos últimos anos. Vários fatores poderiam ser levantados para tentar explicar este possível decréscimo, mas todos eles certamente seriam meras suposições. Vale assim, o que foi discutido anteriormente, em que um número maior de horas de observação e a utilização de diferentes métodos de amostragem resulte em índices similares à última década ou comprovar-se-á que efetivamente está havendo um declínio na densidade de várias espécies de aves.

Deve-se ainda ser ressaltado que o número menor de espécies registrado no último ano se comparado com o número observado há 18 anos, pode estar associado: 1) à diminuição na densidade das aves, de uma forma geral; 2) a diferenças nas atividades das aves ao longo dos últimos meses; e 3) reais mudanças na composição específica associadas a diversos fatores, sendo a interferência humana possivelmente um deles. Um importante fato constatado é que durante os meses da estação reprodutiva das aves (primavera e verão) o rendimento da metodologia é muito superior à estação não-reprodutiva, talvez devido à alta movimentação das aves associado ao maior volume de vocalizações.

Constatou-se, em 12 visitas à Fazenda Rio Claro, um total de 885 registros, perfazendo um média de 73,75 espécies/visita. Esta média pode aparentemente ser considerada baixa, mas considera-se o seguinte: 1 ) esforço amostral de $8 \mathrm{~h}$ /visita (con- 
tra 15 horas de Vielliard \& Silva 1990, por exemplo); 2) os mesmos observadores ao longo de toda amostragem; 3 ) as amostragens ficaram restritas particularmente às adjacências da mata e ambientes antropizados e não toda área da fazenda.

O número de espécies registradas em cada visita variou de 42 (agosto de 2001) a 174 (setembro do mesmo ano), sendo que em fevereiro de 2002 registraram-se 111 espécies. Assim, em apenas duas visitas constatou-se cerca de $80 \%$ do total de espécies registradas para a Fazenda Rio Claro. Isto poderia ser explicado pelo fato de que setembro é o mês em que se inicia a atividade reprodutiva da maioria das aves no Hemisfério Sul.

Outro fator interessante refere-se às flutuações observadas na comunidade de aves entre visitas consecutivas, fato este relatado também por VielliaRd \& Silva (1990). Já a variação dos totais acumulados por espécies em meses consecutivos não evidenciou um acréscimo significativo a partir da terceira visita, fato este considerado normal uma vez que existe uma tendência à estabilização no número de espécies registradas com o passar do tempo e com um maior número de observações (WILLIS \& ONIKI 1981). Mesmo assim, a curva cumulativa não se estabilizou como vimos anteriormente.

\section{Levantamento quantitativo}

Foram realizadas 60 amostras durante os 12 meses, tendo sido registradas 74 espécies e 761 contatos, com uma média de 12,7 contatos/amostra. Aleixo \& Vielliard (1995) obtiveram uma média de 23,2 contatos/amostra na mata de 250 ha da Fazenda Santa Genebra; Vielliard \& Silva (1990), após 23 meses de amostragem e 110 amostras, obtiveram uma média de cerca de 20 contatos/amostra.

Na Fazenda Rio Claro, a média de contatos por mês variou de 7,6 (dezembro de 2001) a 17,6 (fevereiro de 2002) (Tab. III).

Pode-se observar que os índices estiveram sempre na marca dos dois dígitos exceto em dezembro de 2001 quando choveu muito durante a amostragem e provavelmente por esta razão o valor esteve muito inferior aos registrados nos demais meses. Outro fator de destaque refere-se aos valores das médias dos índices que estão acima da média geral registrada $(M=12,7)$; em seis dos doze meses amostrados a média é maior que a média geral: setembro, outubro, janeiro, fevereiro, maio e junho, sendo os quatro primeiros na estação reprodutiva (setembro a março) e dois meses fora deste período. A média de maio, por exemplo, foi maior que a de janeiro; este fato poderia ser explicado pelo índice de pluviosidade registrado no mês de janeiro.

O número máximo de espécies observado em uma manhã de amostragem por pontos foi de 32 com uma variação entre 21 (dezembro de 2001) a 32 espécies (setembro de 2001). Tais registros são coincidentes com aqueles obtidos para o número de indivíduos, exceto no caso de maio de 2002 em que o número de espécies foi mínimo $(\mathrm{n}=21)$, mas o número de indivíduos foi igual a 72. Este fato também foi observado por Vielliard \& Silva (1990) no mês de julho de 1986 quando um aumento do número de indivíduos não foi acompanhado de um aumento na composição específica. Este fato talvez ilustre a movimentação das aves e não a modificação ou acréscimo na riqueza de espécies. A média do número de espécies registrada durante o censo quantitativo foi de 26,7 espécies.

\section{Índice pontual de abundância}

O índice pontual de abundância apresentou variação de 0,001 (1 contato) a 0,070 (53 contatos) com uma média de 0,014 (equivalente a 10 contatos/espécie) (Tab. I).

A curva cumulativa do número de espécies por ordem decrescente de abundância (Fig. 2) mostra que existem cerca de $10 \%$ das espécies com índice de detecção maior que a média ( $n=8$ espécies), 60\% das espécies $(n=45)$ com baixa detecção com índices variando até dois contatos e 30\% (n = 21) das espécies com índice de deteç̧ão maior que um e menor que 7. Em termos ecológicos pode-se dizer que poucas espécies são abundantes na mata estudada e que a grande maioria apresenta pequena abundância. Observa-se aqui o mesmo perfil que um ambiente de mata tropical onde se tem um grande número de espécies e um número pequeno de indivíduos/espécies, exceção de algumas espécies que naturalmente são mais abundantes, tais como, neste caso: Basileuterus culicivorus (Deppe, 1830), B. leucoblepharus (Vieillot, 1817), Cyclarhis gujanensis Baird, 1866, Corythopis delalandi (Lesson, 1830), Synallaxis ruficapilla Vieillot, 1819, Conopophaga lineata Ménétriès, 1885, Thamnophilus caerulescens Vieillot, 1816, Pytilus fuliginosus (Daudin,1800) e Chiroxiphia caudata (Shaw \& Noder, 1793). Tais espécies representam cerca de $40 \%$ do número total de contatos registrados e se mostraram mais abundantes também em outros trabalhos: Aleixo \& Vielliard (1995) encontraram o maior valor de IPA para uma única espécie de ave na mata de Santa Genebra - 2,584 para Basileuterus culicivorus. Em todos os casos, entretanto, estes autores encontraram o mesmo perfil para mata tropical, ou seja, um grande número de espécies com baixa abundância e um pequeno número com alta abundância, o mesmo encontrado na mata em questão.

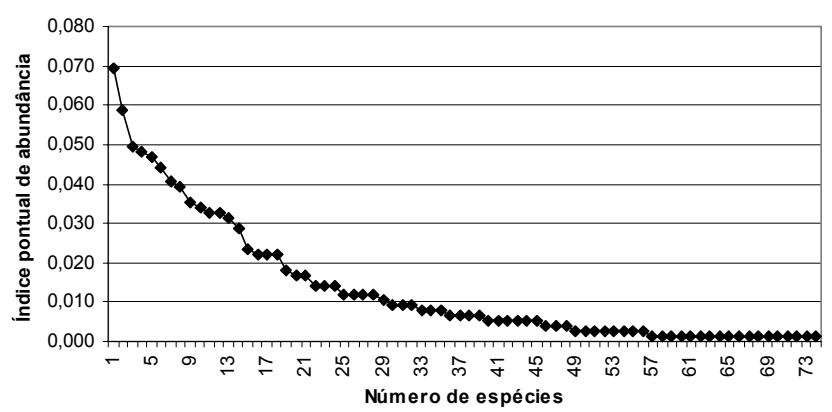

Fig. 2. Curva cumulativa do número de espécies de aves registradas na Fazenda Rio Claro, Lençóis Paulista, São Paulo, por ordem decrescente de abundância

Das espécies registradas por Vielliard \& Silva (1990) em seu levantamento quantitativo realizado na mata do Rincão 
Tabela III. Variação mensal nas médias de contatos e nos índices de diversidade $\left(\mathrm{H}^{\prime}\right)$ da comunidade de aves, valores de diversidade $\left(\mathrm{H}^{\prime}\right)$, diversidade máxima (Hmáx) e eqüidistribuição (E) mensais obtidos no levantamento quantitativo na fazenda Rio Claro, Lençóis Paulista, São Paulo no período de agosto de 2001 a julho de 2002.

\begin{tabular}{lrrrrrrrrrrrr}
\hline \multicolumn{1}{c}{ Meses } & Ago & Set & Out & Nov & Dez & Jan & Fev & Mar & Abr & Mai & Jun & Jul \\
\hline Médias dos IPA & 11,60 & 15,00 & 14,60 & 12,40 & 7,60 & 12,80 & 17,60 & 11,20 & 10,80 & 14,40 & 13,20 & 11,00 \\
Índices de diversidade (H') & 3,11 & 3,27 & 3,23 & 3,33 & 2,91 & 3,19 & 3,20 & 3,02 & 3,01 & 2,89 & 3,02 & 3,01 \\
Hmáx & 3,33 & 3,46 & 3,46 & 3,46 & 3,04 & 3,29 & 3,40 & 3,21 & 3,21 & 3,04 & 3,17 & 3,17 \\
E & 0,93 & 0,94 & 0,93 & 0,96 & 0,96 & 0,97 & 0,94 & 0,94 & 0,94 & 0,95 & 0,95 & 0,95 \\
\hline
\end{tabular}

na Fazenda Rio Claro, apenas onze espécies que ocorrem em mata não foram registradas nesse trabalho. As demais ocorrem em áreas abertas, em meio aquático, em bordas de mata e adjacências e foram registradas no levantamento qualitativo ou exaustivo. Daquelas observadas pelos autores citados, apenas quatro não foram registradas sequer no levantamento exaustivo. Isto não que dizer que as espécies estão extintas na área, mas apenas que não foram constatadas no período amostral em questão e que, talvez com mais amostras, tais espécies poderiam ser detectadas. Os índices pontuais de abundância variaram relativamente entre as espécies registradas por aqueles autores e neste trabalho, mas deve-se considerar que os referidos autores realizaram aproximadamente o dobro das amostras. Por outro lado, os índices obtidos para as espécies mais abundantes foi similar e oito entre dez espécies registradas nesse trabalho foram registradas por aqueles autores como mais abundantes (ou seja, um índice de $80 \%$ de similaridade em maior abundância): Basileuterus culicivorus, B. leucoblepharus, Cyclarhis gujanensis, Synallaxis ruficapilla, Conopophaga lineata, Thamnophilus caerulescens, Pytilus fuliginosus e Chiroxiphia caudata.

Observou-se na Fazenda Rio Claro que cerca de 35\% do total de espécies detectadas na amostragem qualitativa foram detectadas na amostragem quantitativa. Essas diferenças são esperadas, já que a grande maioria das espécies de borda de mata e adjacências não seriam encontradas no censo por pontos (quantitativo) realizado no interior da mata. O resultado poderia ser ainda menor para a mata da Fazenda Rio Claro como observaram Vielliard \& Silva (1990) com cerca de 30\%.

\section{Diversidade}

O gráfico da variação mensal da riqueza específica e da abundância de aves (Fig. 3) evidencia um crescimento a partir de setembro até novembro e uma queda acentuada em dezembro no número de espécies; tal queda pode ser explicada devido à pluviosidade no mês de dezembro. O interessante é que o mês de dezembro modificou os parâmetros de riqueza quando do levantamento qualitativo, da média do número de espécies e da média da abundância destas, quando do levantamento quantitativo (censo por Pontos de Escuta); assim, não poderia ser diferente o resultado deste mês face à riqueza mensal comparada quando realizado o censo por pontos. O fato mais im-

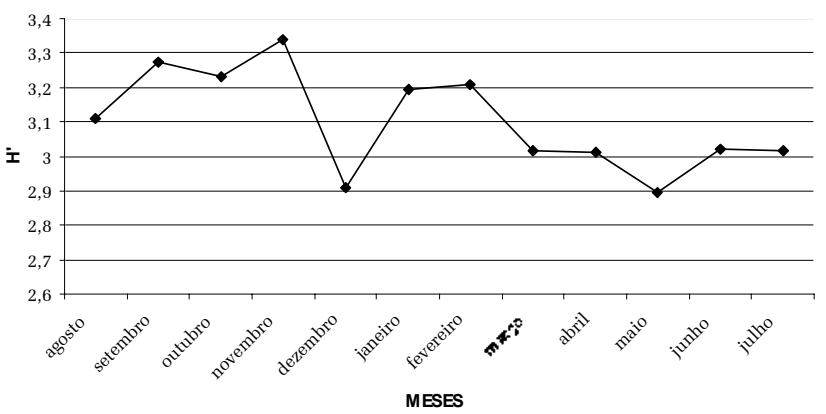

Fig. 3 Variação mensal da riqueza e abundância da comunidade de aves na Fazenda Rio Claro, Lençóis Paulista, São Paulo, entre agosto de 2001 a julho de 2002

portante disso é que dezembro normalmente é um mês em que se esperaria uma alta riqueza específica, alta abundância, alta média de riqueza e de abundância e em conseqüência, alto índice de diversidade. Infelizmente a pluviosidade modificou esses índices mostrando, de maneira provavelmente incorreta, os dados do mês de dezembro. Naturalmente a curva de riqueza do gráfico cresce em janeiro e atinge um pico em fevereiro para não mais se manter até o final das amostras. Setembrooutubro-novembro representam um patamar definido (talvez dezembro também representasse) e fevereiro representa outro patamar. A queda a partir de março poderia ser explicada pelo fim do período reprodutivo das aves, diminuição das atividades de vocalização e talvez diminuição no deslocamento das mesmas. A curva da abundância evidencia uma queda ainda mais acentuada no mês de dezembro no número de indivíduos (acompanhando a de riqueza específica), um patamar extremo em fevereiro e queda a partir de então, exceto no mês de maio; interessante notar que há um acréscimo em setembro, mas uma queda no número de indivíduos em outubro-novembro, mesmo que o número de espécies permanecesse constante. Uma explicação possível seria uma diminuição nas atividades das aves que estão em alguma fase reprodutiva (postura, incubação, cuidados à prole, dentre outros) em que normalmente um membro do casal se desloca com mais freqüência que o outro; outra possibilidade seria uma diminuição no coeficiente de detecção dos indivíduos pelo observador, já que o número de 
espécies se manteve constante. De qualquer forma, constata-se por meio do gráfico que o pico de 70 indivíduos foi ultrapassado nos meses de setembro, outubro, fevereiro e maio somente.

A figura 4 mostra a variação no índice de diversidade ao longo do período amostral e retrata o seguinte: os índices são compatíveis com a riqueza e a abundância abordados na figura 3, exceto em novembro e fevereiro. Em novembro há uma ligeira queda na abundância, mas o número de espécies mantém-se em um patamar (junto a setembro-outubro).

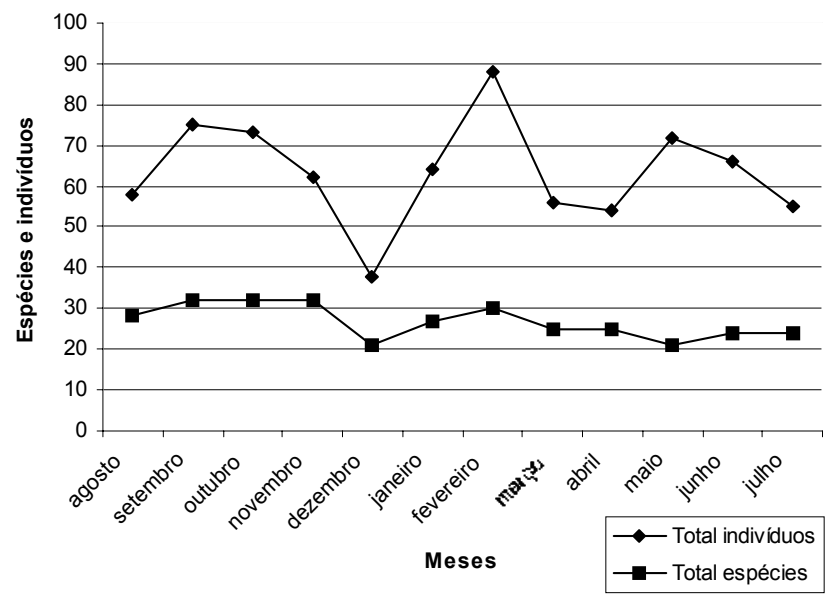

Fig. 4 Variação mensal do índice de diversidade $\left(\mathrm{H}^{\prime}\right)$ da comunidade de aves na Fazenda Rio Claro, Lençóis Paulista, São Paulo, entre agosto de 2001 e julho de 2002.

Observa-se que o índice é maior em novembro, seguido por setembro e outubro (Tab. III). Uma explicação possível seria que um dos componentes da diversidade, no caso a composição específica, manteve o índice alto apesar da menor abundância; todavia, tendo setembro a mesma composição específica e maior abundância, este mês deveria apresentar maior índice de diversidade (a diferença entre os índices é igual a 0,05). A resposta a esta questão talvez esteja no índice de eqüidistribuição discutido abaixo.

$\mathrm{O}$ índice de diversidade geral registrado foi $\mathrm{H}^{\prime}=3,10$. Vielliard \& Silva (1990) obtiveram um índice de $\mathrm{H}^{\prime}=3,89$. Tais autores realizaram 110 amostras e registraram uma riqueza de 111 espécies e uma abundância de 2194 indivíduos em 23 visitas. No presente estudo foram realizadas 60 amostras, registrada uma riqueza de 74 espécies e uma abundância de 761 indivíduos em 12 visitas. A diferença entre os índices é significativa em termos ecológicos já que a diferença média entre os contatos é de $n=7,1$, ou seja, aqueles autores, não obstante o maior número de amostragens, registraram, em média, um maior número de indivíduos que o observado no trabalho atual. Dentre as diversas possibilidades advindas disso duas podem ser destacadas: na época em que foi realizada a amostragem por aqueles autores o número de espécies e de indivíduos era maior que na época atual, razão esta expressa nos índices de diversidade registrados no presente trabalho e há 18 anos por aqueles autores; o coeficiente de detecção das aves foi menor pelos atuais observadores que pelos primeiros autores. Isto pode ter ocorrido por várias razões, como por exemplo, condições climáticas adversas durante as amostragens, capacidade de detecção de espécies foi menor pelos atuais observadores, modificação nas atividades das aves durante todo esse tempo e por último, diminuição efetiva na abundância das aves na mata do Rincão.

Durante a análise dos dados não foi constatada, em qualquer área (Tab. III) ou no habitat amostrado, uma ou mais espécies dominantes ou com uma abundância extremamente maior que as demais. Algumas espécies destacaram-se mostrando um índice pontual de abundância maior que as demais e que foram assim relacionadas. A questão proposta é: seria essa variação maior no índice pontual de abundância, registrado em algumas espécies de aves, suficiente para alterar o coeficiente de diversidade a ponto de questionar o resultado obtido? Para responder a essas questões é necessário reportar-se aos dados obtidos para o índice ou coeficiente de distribuição dessa diversidade (Tab. III) e para a análise das guildas.

A tabela III reflete os valores mensais de eqüidistribuição registrados na Fazenda Rio Claro. A média de todos os valores é $\mathrm{E}=0,95$, ou seja, a distribuição das espécies em todas as amostras mostrou-se constante (a variação é mínima, de $\mathrm{E}=0,93$ a E $=0,97$ ), uniforme e equilibrada. Este valor pode explicar também que, proporcionalmente a uma variação sazonal na composição específica, há um acompanhamento na abundância das espécies e no equilíbrio de todo esse processo, sendo que uma espécie ou conjuntos de espécies não se sobrepõem, em termos de abundância às demais, mesmo com uma flutuação sazonal. Mesmo nos casos em que existem espécies que mostraram um índice pontual de abundância maior que as demais não foi observada qualquer alteração na eqüidistribuição, pois o número de espécies que se apresentaram com maior abundância foi pequeno comparado com o total de espécies registradas. Tal resultado (no caso do E médio), ou tais resultados (no caso do E mensal) ilustram uma comunidade relativamente equilibrada muito embora houve variações significativas na riqueza e abundância (refletidas na diversidade) nas últimas duas décadas, como discutido anteriormente. VieLliard $\&$ SILVA (1990) obtiveram um valor global para a eqüidistribuição de $\mathrm{E}=0,83$ (com um variação até $\mathrm{E}=0,95$ ). Tais autores explicaram este valor como déficit na abundância de certas espécies e excesso de abundância em outras. No único ponto discordante dos autores supracitados, não é possível concordar com tal justificativa uma vez que, retiradas todas as variáveis que normalmente influenciam determinadas distribuições na comunidade de aves, o valor obtido para a eqüidistribuição e considerado baixo por aqueles autores, seria, a nosso ver, devido ao fato de que três diferentes observadores obtiveram os 
dados isoladamente; certamente isso teve influência na distribuição dos indivíduos dentro das espécies mesmo que todos tenham utilizado os mesmos critérios (Bibby \& Burgess 1993). A capacidade de detecção de cada um deles difere e isto somente se comprova nos dados de eqüidistribuição, uma reunião e conclusão de todos os dados obtidos. Os próprios autores (Vielliard \& Silva 1990: 148) de certa forma concordam com isso, pois relatam que o valor obtido representa aquele esperado para matas temperadas. Uma diferença significativa na eqüidistribuição se tem quando se estudam aves migratórias, particularmente marinhas e aquáticas, em que num determinado período de amostragem podem ser registradas milhares de indivíduos pertencentes a algumas espécies e poucos indivíduos pertencentes a muitas espécies. Trata-se de um retrato casual da avifauna naquele instante como foi descrito por NASCIMENTO (1994) com dados coletados por muitos autores, inclusive por Donatelli (ver pág. 17) na usina da CESP em Ibitinga, São Paulo $\left(21^{\circ} 45^{\prime} \mathrm{S} ; 49^{\circ} \mathrm{W}\right)$. Desta forma, não se pode esperar que o mesmo ocorra em matas exceto em casos extremos ou quando vários observadores obtêm as amostras. Todavia, o índice obtido por aqueles autores não pode ser considerado tão baixo a ponto de compará-lo a matas temperadas. Infelizmente não dispomos dos dados relativos àquelas espécies registradas durante o levantamento quantitativo de VieLliard \& SiLva (1990) para poder compará-los com os dados obtidos neste estudo. Conseqüentemente, não se pode avaliar quais espécies tiveram as suas populações diminuídas ou aumentadas durante as duas últimas décadas na área em questão.

\section{Guildas}

\section{Categorias alimentares}

Os resultados das categorias alimentares são mostrados na tabela IV, onde primenramente é ilustrada a distribuição das categorias alimentares de acordo com a riqueza registrada no levantamento qualitativo ou exaustivo. Tal levantamento englobou o habitat amostrado e áreas adjacentes, incluindo-se as antrópicas. Em seguida a tabela ilustra exclusivamente as categorias alimentares das aves registrados no levantamento quantitativo (Pontos de Escuta). As duas porções dessa tabela serão comparadas com o intuito de saber se a composição das categorias alimentares mudou entre os levantamentos qualitativo e quantitativo.

Os resultados serão discutidos paralelamente a todas as comparações realizadas para que seja possível ter uma idéia da dinâmica das categorias alimentares 1) na fazenda e 2) entre parâmetros (riqueza e abundância).

Pode-se observar que as aves insetívoras representam quase a metade (44\%) de todas as aves registrados no levantamento qualitativo; as aves frugívoras têm uma representação bem mais modesta em relação às insetívoras, sendo que aproximadamente uma em cada quatro aves pertence a esta categoria alimentar (24,9\%); entretanto, apresentam maior porcentagem em relação às onívoras $(16,4 \%)$. As carnívoras têm pouca representatividade $(8,5 \%)$ e são representadas basicamente por gaviões e falcões; as aves nectarívoras são representadas pelos beija-flores e contam com uma parcela muito pequena, basicamente restrita a ambientes antropizados na fazenda. As detritívoras, representadas quase em sua totalidade por urubus, tem a menor representatividade nas categorias alimentares $(1,4 \%)$.

Em termos gerais, pode-se dizer que a distribuição das categorias alimentares está bem equilibrada (maior porcentagem de aves insetívoras, seguida de frugívoras, onívoras, carnívoras, nectarívoras e detritívoras), comum em áreas de matas tropicais preservadas como já constataram anteriormente BierregaArd \& Stouffer (1997). Segundo Sick (1997), a alta porcentagem de espécies de aves insetívoras registrada é padrão para a região tropical. Constatou-se que a grande maioria de aves insetívoras são Passeriformes (55\%), sendo a família mais representativa nesta categoria os Tyrannidae. Em relação as aves frugívoras, constata-se que a porcentagem de aves não-Passeriformes e Passeriformes é a mesma (25\%), um bom indicativo da conservação da mata com o passar dos anos, pelo fato de que possivelmente exista produção contínua de alimentos ao longo dos anos, para as frugívoras de pequeno e médio porte. Outro indicativo é a presença de aves frugívoras de grande porte que se alimentam na mata e nas áreas adjacentes como, por

Tabela IV. Categorias alimentares da comunidade de aves em termos de riqueza registradas na fazenda Rio Claro, Lençóis Paulista, São Paulo, com subdivisões para aves não-Passeriformes (NP) e Passeriformes (P); (T) Total.

\begin{tabular}{|c|c|c|c|c|c|c|c|c|c|c|c|c|}
\hline \multirow{2}{*}{ Categorias } & \multicolumn{6}{|c|}{ Riqueza } & \multicolumn{6}{|c|}{ Abundância } \\
\hline & NP & $\%$ & $\mathrm{P}$ & $\%$ & $\mathrm{~T}$ & $\%$ & NP & $\%$ & $P$ & $\%$ & $T$ & $\%$ \\
\hline Insetívoro & 22 & 27,1 & 73 & 55,0 & 95 & 44,6 & 5 & 18,5 & 32 & 68,0 & 37 & 50,0 \\
\hline Carnívoro & 18 & 22,2 & 0 & 0 & 18 & 8,5 & 5 & 18,5 & 0 & 0 & 5 & 6,7 \\
\hline Frugívoro & 20 & 25,0 & 33 & 25,0 & 53 & 24,9 & 9 & 33,3 & 7 & 14,9 & 16 & 21,6 \\
\hline Onívoro & 10 & 12,3 & 25 & 19,0 & 35 & 16,4 & 5 & 18,5 & 8 & 17,1 & 13 & 17,6 \\
\hline Nectarívoro & 8 & 9,9 & 1 & 1,0 & 9 & 4,2 & 3 & 11,2 & 0 & 0 & 3 & 4,1 \\
\hline Detritívoro & 3 & 3,5 & 0 & 0 & 3 & 1,4 & 0 & 0 & 0 & 0 & 0 & 0 \\
\hline Totais & 81 & 100 & 132 & 100 & 213 & 100 & 27 & 100 & 47 & 100 & 74 & 100 \\
\hline
\end{tabular}


exemplo, Penelope superciliaris Spix, 1824. A presença de aves generalistas neste caso não representa um grande percentual geral $(16,4 \%)$, tampouco para aves não-Passeriformes $(12,3 \%)$ como para as Passeriformes (19\%).

Os dados para a abundância na Fazenda Rio Claro correspondem ao que foi obtido para a riqueza (Tab. IV). A ordem decrescente das porcentagens das categorias alimentares foi a mesma. A cada duas aves registradas na mata do Rincão, uma era insetívora sendo que a grande maioria destas eram Passeriforme. A maior parte das aves frugívoras pertencia aos nãoPasseriformes, o que indica que os frugívoros de grande porte ainda estão presentes na mata, como pôde-se constatar. Bom indicativo também foi obtido com o baixo percentual de onívoros, basicamente representantes de copa e borda, o que sugere que a borda da mata não avançou significativamente para o interior da mata como ocorre com áreas mais degradadas, sujeitas a intervenção humana direta (desmatamento periférico). Em relação às demais categorias, observa-se um baixo valor para as aves carnívoras, fato este esperado para uma mata preservada, pois a porcentagem destas aves não é significativa em ambientes florestados, mas em ambientes abertos (МоттA 1990). Os detritívoros registrados passavam sobre a mata ou estavam pousados em qualquer copa de árvore pertencente à mata e por esta razão foram também registrados, sendo o valor obtido perfeitamente compatível.

Na Fazenda Rio Claro constata-se que há mais aves insetívoras no interior da mata do Rincão que externas a ela, fato este esperado de certa forma, sendo que externamente há uma maior porcentagem de aves insetívoras não-Passeriformes $(27,1 \%)$ e internamente maior porcentagem de aves insetívoras Passeriformes (68\%). A maior porcentagem de aves frugívoras externamente à mata $(24,9 \%)$ pode ser explicada devido às áreas antropizadas encontradas na Fazenda Rio Claro, as quais atraem tais aves. Todavia, a distinção básica, como ressaltado acima, está na diferenciação das aves frugívoras de grande porte que em sua maioria $(33,3 \%)$, encontra-se na mata, ou seja, a cada três aves frugívoras na mata, uma é de grande porte. Além disso, as aves frugívoras não-Passeriformes abordadas adjacentes à mata podem ser registradas dentro da mesma, fato este que elevou o índice percentual de tais aves na tabela IV da riqueza específica. Os dados não apontam diferenças significativas entre as aves onívoras externas (exaustivo) e dentro da mata (quantitativo); isto significa uma estabilidade, já que não há maior porcentagem destas aves no interior da mata, o que poderia sugerir alguma alteração. Mais ainda, tais espécies de aves onívoras são basicamente distintas, como por exemplo, Trogon surrucura Vieillot 1817, que só ocorre dentro da mata e Elaenia flavogaster (Thunberg, 1822) a qual só ocorre em ambientes abertos, o que reforça a idéia de estabilidade. O levantamento exaustivo acusou maior porcentagem de aves carnívoras (todas não-Passeriformes) em áreas adjacentes à mata; este fato já era esperado uma vez que grande parte dessas aves pertencem às famílias Accipitridae e Falconidae, mais comumente encontradas em áreas abertas e em menor porcentagem em matas. A diferença numérica é significativa: 18 espécies de aves carnívoras em áreas adjacentes contra cinco na mata. Os Trochilidae são encontrados em grande número não somente dentro da mata como em áreas abertas naturais e antropizadas. Por esta razão os valores encontrados para a categoria alimentar dos nectarívoros é equilibrada e coerente com os demais resultados.

Em relação ao parâmetro categoria alimentar, de uma forma geral, a análise de riqueza e abundância evidenciaram um equilíbrio entre o que foi registrado externamente e internamente à mata; além disso, muitas espécies das categorias de frugívoras e onívoras são exclusivas de mata.

\section{Estratificação}

Os dados das guildas referentes à estratificação foram obtidos apenas nos ambientes em que o censo quantitativo foi realizado, ou seja, na mata. Justifica-se tal procedimento porque desejava-se saber como está distribuída a estratificação das categorias alimentares nos ambientes amostrados e não em áreas adjacentes ou antrópicas. A tabela $\mathrm{V}$ mostra esses resultados.

Tabela V. Categorias alimentares da comunidade de aves e estratos ocupados na Fazenda Rio Claro, Lençóis Paulista, São Paulo.

\begin{tabular}{lccccc}
\hline & $\begin{array}{c}\text { Insetívoro } \\
(\%)\end{array}$ & $\begin{array}{c}\text { Frugívoro } \\
(\%)\end{array}$ & $\begin{array}{c}\text { Onívoro } \\
(\%)\end{array}$ & $\begin{array}{c}\text { Carnívoro } \\
(\%)\end{array}$ & $\begin{array}{r}\text { Nectarívoro } \\
(\%)\end{array}$ \\
\hline Sup./copa & 28 & 42 & 56 & 75 & 25 \\
Sub-bosque & 52 & 25 & 44 & - & 75 \\
Solo & 5 & 33 & - & 25 & - \\
Vertical & 15 & - & - & - & - \\
\hline
\end{tabular}

As aves insetívoras são mais representativas no sub-bosque, fato este que corrobora a boa preservação da mata do Rincão, uma vez que grande parte dessas aves é exclusiva de mata (por exemplo, Formicariidae, Tyrannidae, Parulidae); as aves de sub-bosque são aquelas que permanecem nos fragmentos e por esta razão são vulneráveis às alterações provindas do meio externo, como observaram BiERREGAARd \& STOUfFer (1997). O mesmo se pode dizer em relação as aves frugívoras de copa e também do solo, incluindo-se neste caso uma disponibilidade de alimentos distribuídos ao longo do ano. No primeiro caso, as aves frugívoras participam de bandos mistos de forrageamento, várias vezes observados em nosso levantamento. As espécies de solo são geralmente as de médio porte, como aquelas pertencentes ao gênero Crypturellus e à família Columbidae. Áreas com processo de degradação apresentam uma comunidade de aves frugívoras amplamente distribuídas e de composição distinta das encontradas. Foi observado na mata do Rincão, frugívoros de grande porte, pertencentes às famílias Cracidae, Ramphastidae e Psittacidae. Através desses resulta- 
dos pode-se verificar que a referida mata possui condições de manter espécies que se alimentam de frutos durante o ano todo, incluindo as de grande porte. A porcentagem de onívoros de copa, tais como Baryphthengus ruficapillus (Vieillot, 1818) e Trogon surrucura Vieillot, 1817, indica uma exclusividade no hábito alimentar dessas aves no referido estrato, pois são aves que não são encontradas fora da mata.

De acordo com WiLlis (1979) alterações ambientais podem levar a uma tendência ao aumento de aves onívoras e possivelmente de insetívoras menos especializadas e decréscimo de frugívoras e insetívoras mais especializadas. Os nectarívoros de sub-bosque podem sofrer influência do tamanho da área, tais como os Trochilidae que necessitam de áreas maiores para dispersão (BierregaArd \& Stouffer 1997). No caso da mata do Rincão observou-se que estão bem representados, principalmente as de sub-bosque, mais um fator que vem corroborar a boa condição de conservação da mata.

Áreas fragmentadas de floresta nativa têm grande importância para a sobrevivência de várias espécies que dependem deste ambiente, seja para abrigo, alimentação ou ainda nidificação em alguma época do ano. A preservação da vegetação nestas áreas, bem como de seus propágulos, podem garantir os esforços necessários para um futuro reflorestamento (LAMB et al. 1997). Mais ainda, a ausência de uma vegetação característica de uma área florestada no entorno de matas e cerradões pode contribuir para sua degeneração, somando-se à ação de vento, chuvas e queda natural das árvores, poderia prejudicar as espécies do interior de tais áreas. Mesmo pequenos remanescentes florestais podem conter espécies com prioridade de conservação (como é o caso da área citada acima), tais como polinizadores e dispersores de sementes. A questão que se impõe é: o que se pode fazer, a médio prazo, para recuperar tais áreas e assim evitar a extinção local de determinadas populações? Uma resposta provável a esta questão será endereçada sob a forma de sugestões a serem apresentadas mais adiante.

\section{Espécies ameaçadas e provavelmente ameaçadas}

Das aves ameaças de extinção no Estado de São Paulo foram registradas as seguintes na área de estudo: Primolius maracana (Vieillot, 1816), com distribuição irregular no Estado, concentra-se apenas em algumas áreas, como na Estação Ecológica dos Caetetus (EECa), entre os municípios de Gália e Alvinlândia, onde apresenta grande abundância (observação pessoal do primeiro autor); Amazona aestiva (Linnaeus, 1758), mais concentrada em algumas áreas do oeste do Estado de São Paulo e abundante no Estado do Mato Grosso do Sul (observação pessoal do primeiro autor); Melanopareia torquata Hellmayr, 1924, raro nos cerrados do Estado de São Paulo e Mato Grosso do Sul e mais comum no Estado de Goiás; Antilophia galeata (Lichtenstein, 1823), raro no Estado de São Paulo, sendo encontrado em áreas de mata e capoeiras; Procnias nudicollis (Vieillot, 1817), outrora comum nas matas paulistas, restringe-se à mata costeira e à grandes fragmentos desde que haja alimento disponível (frutos); Oryzoborus angolensis (Linnaeus,
1766), das mais raras do Estado de São Paulo devido à procura por passarinheiros. Basicamente restrito ao oeste paulista, o curió é de difícil localização no centro-oeste, mas ainda há indivíduos em áreas isoladas na Fazenda Rio Claro; Saltator atricollis Vieillot, 1817, com distribuição restrita ao oeste paulista na fronteira do Estado do Mato Grosso do Sul é raro e foi registrada na Fazenda Rio Claro em área aberta próxima à estrada que conduz à mata do Rincão; Passerina brissonii, espécie ainda presente na região centro-oeste paulista com vários registros em muitas localidades (observação pessoal do primeiro autor), inclusive na Fazenda Rio Claro.

\section{CONSIDERAÇÕES FINAIS}

O estudo da riqueza de espécies, da abundância e conseqüentemente da diversidade na mata do Rincão da Fazenda Rio Claro mostrou que: 1 ) a diferença encontrada no número total de espécies registradas neste trabalho e de outros autores pode ser basicamente dependente de uma amostragem maior na referida área; 2) as espécies de aves registradas em nosso trabalho e não registradas nos anteriores são basicamente de ocorrência ocasional; 3 ) o índice de similaridade entre os dados aqui obtidos e de outros autores foi considerado elevado $(82 \%) ; 4)$ a comunidade de aves registrada na mata do Rincão durante o levantamento quantitativo (por Pontos de Escuta) encontra-se relativamente estável, equilibrada e uniforme seja: a) pelo número de espécies registrado; b) pela qualidade das espécies (exclusivas de mata, especialistas em várias categorias alimentares presentes e distribuídas pelos estratos da mesma); c) pelo índice pontual de abundância relativo obtido nas 60 amostras e pela média de contatos/amostra; d) pelo relativo alto índice de diversidade, diversidade máxima e eqüidistribuição; e) pela distribuição equilibrada das categorias alimentares em seus vários estratos (aves insetívoras e frugívoras especializadas); e f) pela presença de aves insetívoras de sub-bosque e frugívoras de copa e sub-bosque exclusivas de ambientes florestados.

As sugestões para a conservação da Mata do Rincão são as seguintes: 1) monitoramento periódico da comunidade de aves e comunidades de vertebrados e de organismos aquáticos de uma forma geral (próximo ou em outros sítios na fazenda). Tal monitoramento não deve ficar restrito à mata, mas aos diversos ambientes que compõem um mosaico na Fazenda Rio Claro; e 2) devido a seu isolamento seria muito apropriado um projeto que ligasse a mata do Rincão às matas adjacentes na mesma fazenda. A possibilidade de comunicar fragmentos de mata formando corredores de fauna seria importante para a recuperação, manutenção e aumento do fluxo gênico (com possibilidade de aumento de densidade e talvez de uma recolonização de certos micro-habitats) entre as populações de aves de sub-bosque em geral e de frugívoras especializadas em particular. Os corredores de fauna são, atualmente, uma saída para a manutenção da diversidade e conservação do patrimônio de vida selvagem do país.

Revista Brasileira de Zoologia 21 (1): 97-114, março 2004 


\section{AGRADECIMENTOS}

À Duratex S/A, Lençóis Paulista, em nome de José Luiz da Silva Maia, diretor de Meio Ambiente, pela oportunidade de desenvolvimento do projeto nas dependências da Duratex S/A e aos funcionários pela ajuda e atenção durante a desenvolvimento do projeto.

\section{REFERÊNCIAS BIBLIOGRÁFICAS}

Aleixo, A. \& J. Vielliard. 1995. Composição da dinâmica da avifauna da mata de Santa Genebra, Campinas, São Paulo, Brasil. Revista Brasileira de Zoologia, Curitiba, 12 (3): 493511.

American Ornithologists' Union. 1998. Check list of American Birds. New York, $7^{\text {th }}$ ed., $829 \mathrm{p}$.

Biвby, C.J. \& N.D. Burgess. 1993. Birds Census Techniques. San Diego, Academic Press Inc., 257p.

BierRegaARd JR., R.O. \& P.C. Stouffer. 1997. Understory birds and dynamics habitat mosaics in Amazonian rainforest, p. 138155. In: W.F. Laurance \& R.O. BierregaArd JR. (Eds). Tropical forest remnants: ecology, management, and conservation of fragmented communities. Chicago, University of Chicago Press, 504p.

Blondel, J., C. Ferry \& B. Frochot. 1970. La méthode des indices ponctuels d'abondance (I.P.A.) ou des relevés d'avifaune par "stations d'écoute". Alauda, Paris, 38: 55-71.

CÂmara, I.G. 1990. Atlas da evolução dos remanescentes florestais e ecossistemas associados do domínio da Mata Atlântica no período 1985-1990. São Paulo, Fundação SOS Mata Atlântica, 64p.

DuRAFlora S.A. 1999. Identificação, mapeamento e quantificação de vegetal natural: fazenda Rio Claro (municípios: Lençóis Paulista - Águas de Santa Bárbara). Agudos, Duratex S.A., n. 1620631/01 de Junho de 1999, 9p.

JAKsIC, F.M. 1981. Abuse and misuse of the term "guild" in the ecological studies. Oikos, Lund, 37: 397-400.

Krebs, C.J. 1999. Ecological methodology. Los Angeles, Benjamins Cammings, $2^{\text {nd }}$ ed., 620p.

Lamb, D.; J. Parotta; K. Keenan \& N. Tucker. 1997. Rejoing habitat remnants: restoring degraded rainforest lands, p. 366-385. In: W.F. LAURANCE \& R.O. BieRREgAaRd JR. (Eds). Tropical forest remnants: ecology, management, and conservation of fragmented communities. Chicago, University of Chicago Press, 504p.

LoIselle, B.A. \& J.G. Blake. 1992. Population variation in a tropical bird community. Implications for conservation. BioScience, New York, 42 (11): 838-845.

Magalhães, J.C.R. 1999. As Aves na Fazenda Barreiro Rico. São Paulo, Editora Plêiade, 215p.

MotтA JR., J.C. 1990. Estrutura trófica e composição das avifaunas de três habitats terrestres na região central do estado de São Paulo. Ararajuba, Rio de Janeiro, 1:65-71.

Nascimento, J.L.X. 1994. Censo Neotropical de aves acuaticas 1994. Buenos Aires, Ed. WA, 69p.

SICK, H. 1997. Ornitologia Brasileira. Rio de Janeiro, Nova Fronteira, 912p.

SiLva, W.R. 1998. Bases para o diagnóstico e o monitoramento de Aves no Estado de São Paulo, p. 39-50. In: R.M.C. CASTro; C.A. Joly \& C.E.M. BICUdo (Eds). Biodiversidade do Estado de São Paulo, Brasil: síntese do conhecimento ao final do século $\mathrm{XX}$, 6: vertebrados. São Paulo, Winnergraph, FAPESP, 71p.

VERNER, J. 1981. Measuring responses of avian communities to habitat manipulation. Studies in Avian Biology, Los Angeles: 543-547.

Vielliard, J.M.E. \& W.R. Silva. 1990. Nova metodologia de levantamento quantitativo e primeiros resultados no interior de São Paulo. In: Anais do IV Encontro Nacional dos Anilhadores de Aves, Recife, p. 117-151.

Wiens, J.A. 1994a. Habitat fragmentation: island vs landscape perspectives on bird conservation. The Ibis, London, 137: 97-104.

. 1994b. The ecology of bird communities. Foundations and Patterns. Cambridge, University of Cambridge Press, 539p.

Wilcox, B.A. \& D.D. Murphy. 1985. Conservation strategy: the effects of fragmentation on extinction. The American Naturalist, Chicago, 125: 879-887.

Willis, E.O. 1979. The composition of Avian Communities in Remanescent woodlots in Southern Brazil. Papéis Avulsos de Zoologia, São Paulo 33 (1): 1-25.

Willis, E.O. \& Y. ONIKI. 1981. Levantamento preliminar em treze áreas do Estado de São Paulo. Revista Brasileira de Biologia, Rio de Janeiro, 41 (1): 121-135.

Recebido em 25.VII.2003; aceito em 27.I.2004. 